\title{
Decreased peptidyltransferase activity correlates with increased programmed -1 ribosomal frameshifting and viral maintenance defects in the yeast Saccharomyces cerevisiae
}

\author{
ARTURAS MESKAUSKAS, ${ }^{1}$ JASON W. HARGER, ${ }^{1,2}$ KRISTI L. MULDOON JACOBS, ${ }^{1,2}$ \\ and JONATHAN D. DINMAN ${ }^{1}$ \\ ${ }^{1}$ Department of Cell Biology and Molecular Genetics, University of Maryland, College Park, Maryland 20742, USA \\ ${ }^{2}$ Program in Molecular Biosciences at University of Medicine and Dentistry of New Jersey (UMDNJ)/Rutgers Universities, \\ Piscataway New Jersey 08854, USA
}

\begin{abstract}
Increased efficiencies of programmed -1 ribosomal frameshifting in yeast cells expressing mutant forms of ribosomal protein L3 are unable to maintain the dsRNA "Killer" virus. Here we demonstrate that changes in frameshifting and virus maintenance in these mutants correlates with decreased peptidyltransferase activities. The mutants did not affect Ty1-directed programmed +1 ribosomal frameshifting or nonsense-mediated mRNA decay. Independent experiments demonstrate similar programmed -1 ribosomal frameshifting specific defects in cells lacking ribosomal protein L41, which has previously been shown to result in peptidyltransferase defects in yeast. These findings are consistent with the hypothesis that decreased peptidyltransferase activity should result in longer ribosome pause times after the accommodation step of the elongation cycle, allowing more time for ribosomal slippage at programmed -1 ribosomal frameshift signals.
\end{abstract}

Keywords: Frameshifting; ribosome; virus

Programmed ribosomal frameshift (PRF) events most commonly induce translating ribosomes to slip by a single base in either the $5^{\prime}(-1)$ or $3^{\prime}(+1)$ direction, though examples of ribosomal "hops," "shunts," and "bypasses" have also been documented (for review, see Jacks 1990; Farabaugh 1996; Gesteland and Atkins 1996). Such translational recoding signals have been valuable in addressing questions relating to ribosome structure and function. For viruses that utilize PRF, the efficiencies of frameshift events are critical: They determine the stoichiometry of viral structural to enzymatic proteins available for virus particle assembly, and altering PRF frequencies have dire consequences for virus propagation (for review, see Dinman et al. 1998). Thus, it is important to understand how frameshifting efficiencies are

Reprint requests to: Jonathan D. Dinman, Department of Cell Biology and Molecular Genetics, Microbiology Building, Room 2135, University of Maryland, College Park, MD 20742, USA; e-mail: dinman@umd.edu; fax: 301-314-9489.

Article and publication are at http://www.rnajournal.org/cgi/doi/ 10.1261/rna.2165803. controlled. The most widespread mechanisms involve inducing ribosomes to stall with their associated tRNAs positioned over specific mRNA sequences called "slippery sites" such that, in the event of slippage, the tRNAs are able to base pair with the out-of-frame codon or codons. Although the cis-acting signals are relatively well characterized, the trans-acting factors and the biophysical parameters that contribute to determine PRF efficiencies are less well understood. Genetic, biochemical, molecular, and pharmacological methods have been employed toward this end. In general, parameters that can affect PRF efficiencies include: (1) changes in the residence time of ribosomes at a particular PRF signal and the precise steps of the elongation cycle that such kinetic changes might occur; (2) changes in the stabilities of ribosome-bound tRNAs and/or ribosome catalytic function due to alterations in intrinsic ribosomal components such as ribosomal proteins, rRNAs, and codon:antidcodon interactions; and (3) defects in the abilities of the translational apparatus to recognize and correct errors (for review, see Harger et al. 2002).

The genetic manipulability of the yeast Saccharomyces 
cerevisiae has facilitated the identification of trans-acting factors that can affect frameshifting efficiencies, and researchers in the field have capitalized on the presence of two endogenous viruses of yeast to this end. The Ty 1 retrotransposable element of yeast utilizes a programmed +1 frameshift to synthesize its Gag-pol precursor (Clare et al. 1988; Belcourt and Farabaugh 1990), and changes in +1 PRF efficiencies have inhibitory effects on Tyl retrotransposition frequencies (Xu and Boeke 1990; Kawakami et al. 1993; Balasundaram et al. 1994; Tumer et al. 1998; Harger et al. 2001; Hudak et al. 2001). The 4.6-kb dsRNA L-A virus of yeast utilizes a programmed -1 ribosomal frameshift to produce its Gag-pol fusion protein (Icho and Wickner 1989; Dinman et al. 1991; Tzeng et al. 1992), and changes in -1 PRF efficiencies promote loss of the killer phenotype as a consequence of loss of the 1.6-1.8-kb dsRNA $M_{1}$ satellite virus that encodes the secreted killer toxin (for review, see Wickner 1996). We previously reported that -1 PRF efficiencies were specifically elevated in cells harboring the mak8-1 allele of RPL3 (Peltz et al. 1999), thus providing an explanation for the original observation that mak8-1 cells could not maintain the killer phenotype (Wickner and Leibowitz 1974; Wickner et al. 1982). Two alleles of RPL3 have been heretofore described: The tcm1-1 allele contains a single missense mutation changing tryptophan at position 255 to cystine (Fried and Warner 1981), and the mak8-1 allele contains this mutation plus a second missense mutation changing proline at position 257 to threonine. In this report, we investigated the effects of single and double mutations at this site on $-1 \mathrm{PRF}$, killer virus maintenance, and peptidyltransferase activities in isogenic rpl3 gene deletion strains. We also employed a PCR-based mutagenesis approach to identify and characterize a new allele of RPL3 consisting of mutation of isoleucine 282 to threonine (I282T), which was unable to maintain the yeast killer virus. All of the mak8 alleles promoted increased - 1 PRF efficiencies, and ribosomes isolated from cells expressing these alleles had decreased peptidyltransferase activities. Molecular modeling based on the Haolarcula marismortui 50S ribosomal subunit (Ban et al. 2000) reveals that W255 is the closest amino acid residue in the ribosome to the peptidyltransferase center active site, that P257 is required to form an important bend in a loop that positions W255, and that I282 is in the hydrophobic core at the base of the loop. How these structural changes might specifically affect peptidyltransferase function and -1 PRF is discussed within the context of the recent explosion of information pertaining to ribosome structure and function. Further, based on a recent study showing that deletion of ribosomal protein L41 results in peptidyltransferase defects, we assayed both -1 and +1 PRF in isogenic rpl41-deficient and wild-type strains. The finding that -1 PRF was also specifically stimulated in rpl41-deficient strains supports the general hypothesis that this molecular mechanism can be influenced by peptidyltransfer rates.

\section{RESULTS}

\section{Identification of new mak8 alleles}

The original mak8-1 allele contained two mutations: W255C and P257T (Peltz et al. 1999), and cells expressing this form of the L3 protein had increased -1 PRF efficiencies and were not able to maintain the killer virus. Toward the goal of further analyses of RPL3, we set out to (1) determine the effects of the single mutations, and (2) to identify additional mak 8 alleles. The single mutations were constructed by oligonucleotide site directed mutagenesis, and additional alleles were created using error-prone PCR. The PCR fragments were ligated into a TRP1-CEN6 vector containing the native $5^{\prime}$ and $3^{\prime}$ untranslated region sequences of RPL3, and the resulting plasmids were amplified in Escherichia coli. The library, and the site-directed mutants were introduced into a $\mathrm{Killer}^{+}$rpl3-deletion yeast strain $(r p l 3 \Delta)$, in which the native RPL3 gene was expressed from a URA3-CEN6 vector (pRPL3). After 3 days of growth on medium lacking tryptophan (-trp), colonies were replicaplated to medium containing 5-flouroorotic acid (5-FOA), allowing for selection of loss of the wild-type RPL3 gene. Subsequent replica plating to $4.7 \mathrm{MB}$ killer indicator plates enabled identification of mak8 alleles of RPL3 by loss of the Killer phenotype. After screening over 30,000 colonies, only one novel mutant was identified: a missense mutation that changed isoleucine at position 282 to threonine (I282T). Also identified in the screen were single mutants encoding the W255C and P257T alleles. Approximately $10 \%$ of the mutants were lethal (data not shown), although dominant-lethal mutants would not be identified by the methods employed. Sequence analysis of 20 randomly chosen clones from the library revealed 19 different unique mutants at the nucleotide level, suggesting that the library was mutagenized to saturation. The killer phenotypes of these and of the original RW1906 mak8-1 strain are shown in Figure 1A. Figure 1B shows that loss of the killer phenotype in all of these strains was a consequence of the inability of these cells to support propagation of both the $\mathrm{L}-\mathrm{A}$ and $\mathrm{M}_{1}$ satellite viruses as opposed to a defect in the synthesis or secretion of the $M_{1}$ encoded killer toxin. The differences between the abilities of the L3 mutants expressed in the new $r p l 3 \Delta$ strains and the original mak8-1 strain to maintain L-A may be due to differences in their genetic backgrounds and/or a consequence of episomal expression of RPL3. Thus, in addition to the original mak8-1 allele the single missense mutants (W255C and P257T), as well as I282T appear to be the only viable alleles of $R P L 3$ that are unable to maintain both the L-A and $M_{1}$ dsRNA viruses.

\section{The $r p / 3$ alleles specifically promote increased efficiencies of programmed -1 ribosomal frameshifting}

$M_{1}$ satellite virus propagation defects can stem from other causes distinct from changes in -1 PRF efficiency, for ex- 
A

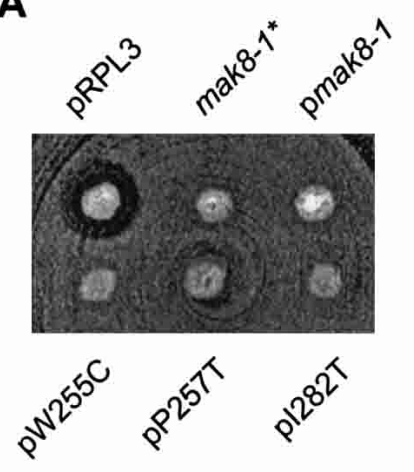

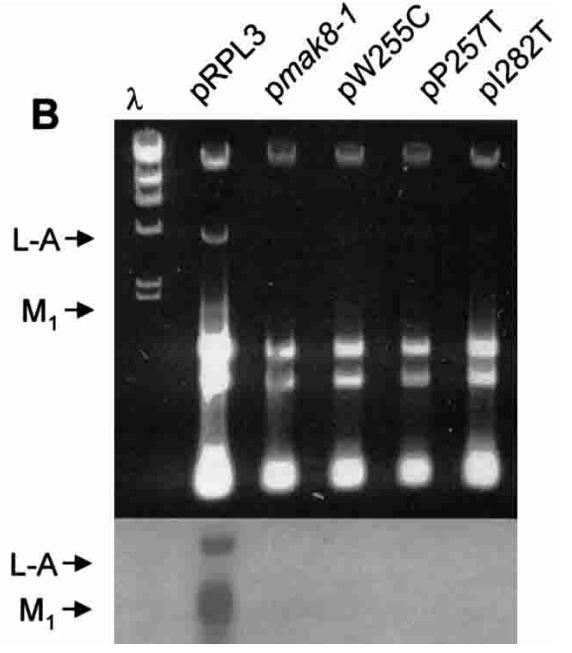

FIGURE 1. The rpl3 mutant alleles cannot propagate the yeast killer virus. $(A)$ Killer assay of strains harboring the wild-type RPL3 gene or mutant alleles. Isogenic $\mathrm{Killer}^{+}$strains containing the RPL3::HIS3 gene disruption and harboring the wild-type RPL3 gene on a URA3-CEN6 plasmid were transformed with TRP1-CEN6 plasmids containing either the wild-type gene or the indicated $r p l 3$ alleles. After selection on medium lacking tryptophan, cells having lost the URA3-CEN6 plasmids were identified by their ability to grow on medium containing 5-FOA. Colonies were then replica plated onto a lawn of cells that are sensitive to the secreted killer toxin produced by the $\mathrm{M}_{1}$ satellite virus of L-A. Killer activity was observed as a zone of growth inhibition around the colonies. mak8-1* is not isogenic with the other strains, but is rather the original mak8-1 isolate (RW1906) used here for comparison. (B) Total RNAs isolated from the isogenic strains described in $(A)$ were separated through a $1.5 \%$ TAE-agarose gel. $\mathrm{L}-\mathrm{A}$ and $\mathrm{M}_{1}$ dsRNAs are indicated as $2.5-$ and 1.8 -kbp bands, respectively. Top panel shows the ethidium bromide stained gel and the bottom panel is a Northern blot of the gel probed for the presence of L-A and $\mathrm{M}_{1}(-)$ strand viral RNAs were performed as previously described (Dinman and Wickner 1994).

ample, ribosomal 60S subunit biogenesis defects (Dinman and Wickner 1994; Ohtake and Wickner 1995). Measurements of programmed ribosomal frameshifting in the mutants using our traditional monocistronic lac $Z$ reporter plasmid system revealed that they all promoted approximately $2-2.5$-fold increases in -1 PRF efficiencies as promoted by an L-A -1 frameshift signal, but that none of these alleles had any effect on Ty1 mediated +1 PRF (Fig. 2A; Table 1).

The monocistronic -1 and +1 frameshift reporter LacZ mRNAs can be considered to be nonsense-containing mRNAs, and increased translational efficiency of a nonsense-containing mRNA has been demonstrated to result as a consequence of defects in the nonsense-mediated mRNA decay (NMD) pathway (Muhlrad and Parker 1999). Thus, it is possible that our observations could have been due to similar defects, although if so, we would have expected to observe similar effects of the mutants on both -1 and +1 PRF instead of on -1 RF alone. Two additional sets of experiments were performed to formally address this possibility.

Bicistronic reporter systems have been used in yeast to control for effects due to variations in mRNA stabilities, half-lives, or translation rates that might differentially affect reporter gene expression from monocistronic reporter sys- tems (Bidou et al. 2000). To this end, we utilized a series of plasmids for the expression of bicistronic dual-luciferase frameshift reporters in yeast. In agreement with data obtained using the lacZbased monocistronic reporters, the bicistronic system revealed that programmed -1 ribosomal frameshifting was also elevated in cells expressing the mutant forms of L3 compared to cells expressing the wild-type $\mathrm{Rpl} 3$ protein, and that Ty1 directed +1 frameshifting was not affected (Fig. 2B; Table 1). Comparison of the results obtained using the mono- and bicistronic reveals two interesting differences: (1) baseline -1 PRF efficiencies were greater with the bicistronic system, and (2) the extents of the increases in -1 PRF in the mutants were smaller (e.g., 1.4-1.7-fold as opposed to 2.0-2.5-fold increases). We speculate that the former may be consequent to elimination of effects due differential stabilities and/or translational efficiencies of the frameshift reporter and 0 -frame control mRNAs. The latter observation could either be due to inherent differences between the systems, or may simply reflect a more accurate picture of the true changes in -1 PRF. If true, then the acceptable "window" of -1 PRF sufficient for virus propagation is considerably smaller than was previously thought. Regardless of the differences in magnitude of the changes in -1 PRF using the different reporter systems, the results demonstrate that the inabilities of cells harboring the different $r p l 3$ alleles to maintain the L-A and $\mathrm{M}_{1}$ viruses are a consequence of increased efficiencies of -1 PRF.

A second set of experiments examined whether expression of the L3 mutants had specific effects on LacZ reporter mRNA steady state abundances, and/or nonspecific effects on the ability of the translational apparatus to recognize and degrade aberrant mRNAs. To address the question of mRNA specificity, RNase protection studies demonstrated that there were no significant differences in the -1 or +1 frameshift to 0 -frame LacZ control steady-state mRNA abundance in the mutants compared to the wild-type control cells, suggesting that the observed changes are specific to -1 PRF and are not due to specific stabilization of the -1 frame reporter message (data not shown). To directly address the question of NMD defects, Northern blot analysis of the endogenous inefficiently spliced $\mathrm{CYH} 2$-precursor mRNA was used to monitor the NMD status of cells expressing the wild-type RPL3 and mutant $r p l 3$ alleles. As a control, the abundance of the CYH2-precursor mRNA was also monitored in a upf1-deletion strain. Figure $2 \mathrm{C}$ shows 
A
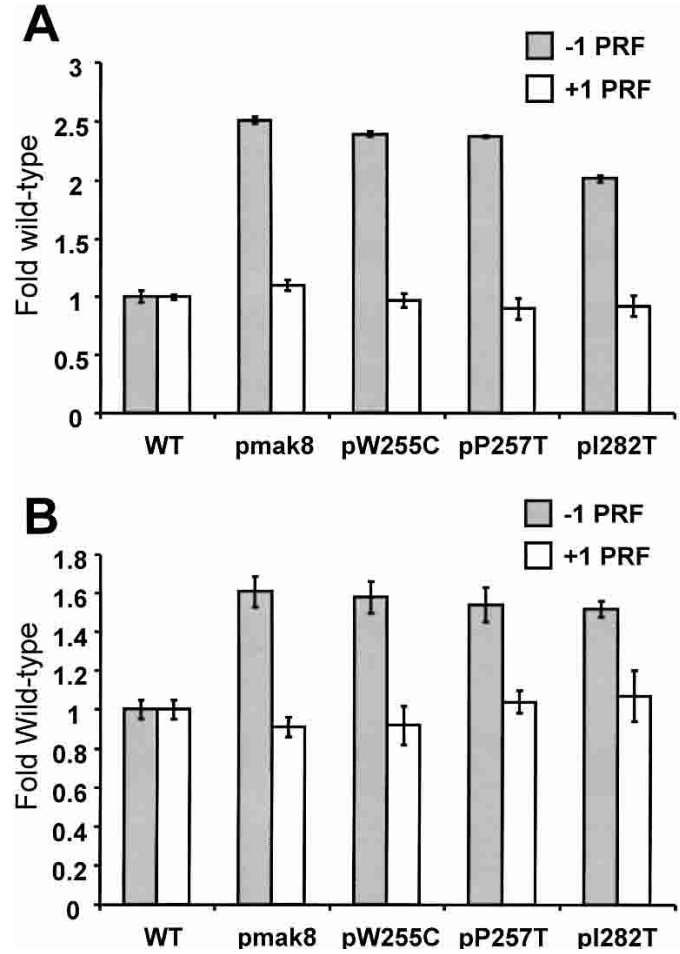

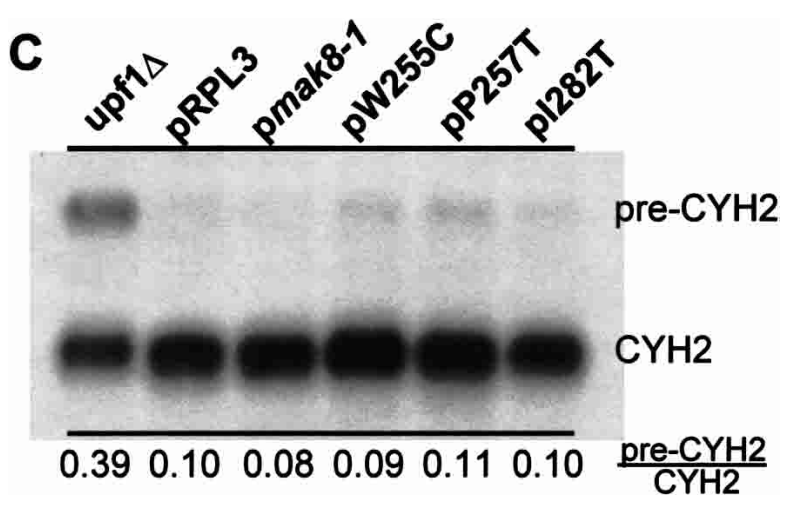

FIGURE 2. Elevated efficiencies of -1 programmed ribosomal frameshifting in cells expressing mutant $r p l 3$. (A) Monscistronic PRF reporter plasmid system. Isogenic strains harboring the TRP1-CEN6-based RPL3 alleles were cotransformed with p0 or p-1 (LEU2-CEN6-based vectors), or p0 or p+1 (URA3-CEN6) and programmed ribosomal frameshifting efficiencies were determined as described (Dinman et al. 1991; Peltz et al. 1999). Changes in frameshift efficiencies are depicted in terms of fold wild-type (see Table 1). Each dataset represents the averages of three individual experiments repeated in triplicate. Error bars denote standard deviations from the means. (B) Bicistronic PRF reporter plasmid system. Isogenic strains harboring the TRP1-CEN6-based RPL3 alleles were cotransformed with bicistronic URA3-CEN6 based Renilla-firefly luciferase 0 -frame, -1 (L-A derived), or +1 (Ty1-derived) reporter vectors. Renilla and firefly luciferase activities of clarified cell lysates were determined using Dual-Luciferase Assay Reagents (Promega) and quantitated using a TD20/20 lumineter (Turner designs). Frameshifting efficiencies were calculated by dividing the firefly/Renilla luminescence ratios from the -1 and +1 programmed frameshift test reporters by the 0 -frame control reporter. Each dataset represents the averages of three individual experiments repeated in triplicate. Changes in frameshift efficiencies are depicted in terms of fold wild-type (see Table 1). Error bars denote standard deviations from the means. (C) Expression of mutant forms of L3 do not affect the nonsense mediated mRNA decay (NMD) pathway. Total cellular mRNA was extracted from mid-logarithmically growing $r p l 3 \Delta$ cells harboring

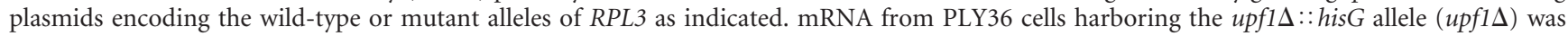
used as a control. Total RNA from each sample was separated through a 1.0\% agarose formaldehyde denaturing gel and transferred to a nylon membrane. The RNA blot was subsequently hybridized with a radiolabeled CYH2 probe as previously described (Cui et al. 1996). The image was visualized, and band intensities were quantitiated using a Molecular Dyanmics PhosphorImager. The locations of the NMD-sensitive CYH2precursor mRNA (pre-CYH2) and of the NMD-insensitive mature CYH2 mRNA are indicated, as are the pre-CYH2/CYH2 signal intensity ratios.

that the rpl3 mutants had no stabilizing effect on $\mathrm{CYH} 2-$ precursor mRNA, demonstrating that the NMD pathway was intact in these strains, and that the effects on -1 PRF cannot be explained by possible NMD defects.

\section{Ribosomes containing the mutant forms of $\mathrm{L3}$ have decreased peptidyltransfer activities}

Ribosomal protein L3 has long been implicated in peptidyltransferase activity (Fahnestock 1975; Bernabeu et al. 1979; Auron and Fahnestock 1981; Fabijanski and Pellegrini 1981; Schulze and Nierhaus 1982; Khaitovich et al. 1999). Our recent models of programmed ribosomal frameshifting predict that inhibition of the peptidyltransfer reaction would increase the amount of time that a ribosome is paused over the frameshift signal after the accommodation step of elongation, increasing the likelihood of -1 ribosomal frameshifting (Harger et al. 2002; Plant et al. 2003). This prediction was previously indirectly validated by the demonstration that the peptidyltransferase inhibitor sparsomycin promoted increased -1 PRF efficiencies and loss of the killer virus in yeast (Dinman et al. 1997). In this study, we utilized the puromycin reaction to test the hypothesis that the defects in peptidyltransferase activities were responsible for the increased -1 PRF efficiencies in cells harboring the mak 8 alleles. The results demonstrate that rates of peptidylpuromycin formation are significantly decreased in ribosomes containing the mutant L3 proteins (Fig. 3). The W255C mutation conferred the greatest peptidyltransfer defect, while the P257T mutation also promoted a strong, but slightly lesser effect. The effects of the two mutations were not additive. The I282T mutation also resulted 


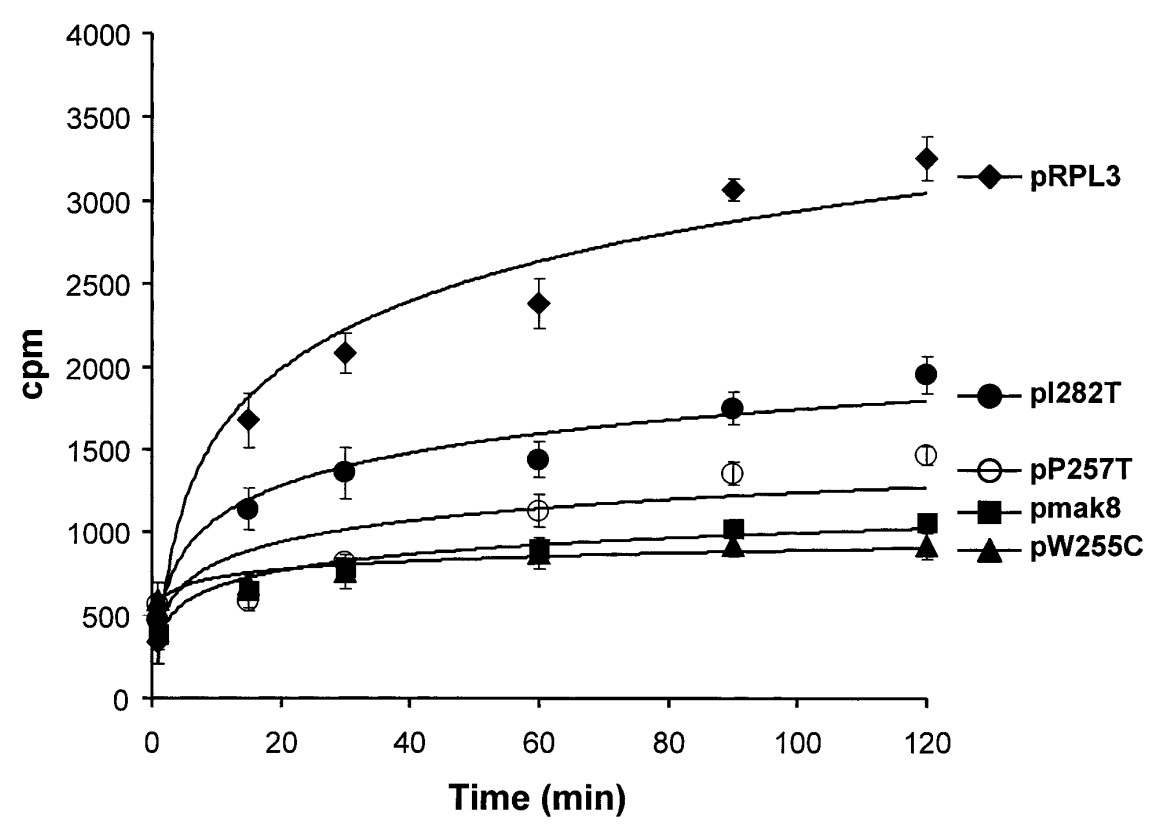

FIGURE 3. Ribosomes containing mutant forms of L3 have decreased peptidyltransferase activities. Time course of the formation of $\left[{ }^{14} \mathrm{C}\right]$ Phenylalanine-puromycin product in assays using ribosomes isolated from isogenic RPL3::HIS3 cells expressing wild-type or mutant forms of L3. Plasmid-borne RPL3 alleles are indicated. EtOAc soluble radioactivity was determined by liquid scintillation counting. Control studies were performed in the absence of puromycin to determine the nonspecific extraction of CACCA $\left[{ }^{14} \mathrm{C}\right] \mathrm{AcPhe}$. Control values (generally less than $2 \%)$ were subtracted from the values obtained in the presence of puromycin. All experiments were performed in triplicate. Data points and error bars indicate mean and standard deviation.

in a significant, although lesser degree of inhibition of peptidyltransferase activity. These results support the hypothesis that decreased peptidyltransferase activities of the ribosomes containing these mutant forms of L3 constitute the biochemical basis for the observed effects of the rpl3 alleles on -1 PRF and killer virus maintenance.

\section{Programmed -1 ribosomal frameshifting is stimulated in ribosomal protein L41-deficient cells}

It has recently been demonstrated that ribosomes lacking ribosomal protein L41 have peptidyltransferase defects (Dresios et al. 2003). With a length of only 25 amino acid, 17 of which are arginine or lysine, yeast ribosomal protein L41 is the smallest and most basic eukaryotic protein (Suzuki et al. 1990). Deletion of the two isogenes encoding this protein (RPL41A and RPL41B) did not affect cell viability or NMD (Yu and Warner 2001; Dresios et al. 2003). As a test of the generality of our hypothesis we assayed both -1 and +1 PRF in the XY5a cells harboring pRS314-RPL41A or the pRS314 vector control (Yu and Warner 2001). The results clearly show that -1 PRF was specifically stimulated 1.51.7-fold in cells lacking L41 and that the presence or absence of L41 had no effect on +1 PRF (Fig. 4; Table 1). These results support the general existence of a correlation between peptidyltransferase defects and increased efficiencies of -1 PRF.

\section{DISCUSSION}

The propagation of many clinically and agriculturally relevant viruses depends upon the availability of precise ratios of viral proteins as determined by the efficiency of PRF. Thus, a better understanding of the molecular mechanisms underlying the control of PRF can contribute toward identifying and characterizing new targets for the rational design of antiviral therapies. There is strong biochemical evidence showing that ribosomal pausing is necessary but not sufficient for efficient -1 PRF (Lopinski et al. 2000; Kontos et al. 2001). We have posited that changes in ribosome pause times at specific steps of the translation elongation cycle would result in changes in both the direction and extent of frameshifting (Harger et al. 2002). Specific to -1 PRF, we have suggested that the mechanism becomes activated at accommodation when $5^{\prime}$ movement of the A-site codon:anticodon pair combines with the inability of the $3^{\prime}$ mRNA pseudoknot to enter the downstream mRNA tunnel to create a local of region tension along the mRNA between these two elements (Plant et al. 2003). Thus, conditions that would increase the amount of time that ribosomes are paused at the frameshift signal after accommodation but before peptidyltransfer should increase the amount of time during which they might slip. Our previous studies using the peptidyltransferase inhibitor sparsomycin and mutants of RPL3 indirectly supported this hypothesis (Dinman et al. 1997; Peltz et al. 1999). In the present study, we demonstrate that increased -1 PRF and decreased peptidyltransfer correlate. The lack of effect of the new L3 mutants described here, and of the L41-deficient strains on both +1 PRF and NMD demonstrate that the observed effects on -1 PRF and virus maintenance are not due to nonspecific effects of altered translational competence of our reporter mRNAs. Although it is possible there is no causal effect between peptidyltransferase activity and programmed -1 ribosomal frameshifting efficiency, the results presented here strengthen the hypothesis by demonstrating a correlation between changes in these two parameters. Another recent study from our laboratory demonstrating a correlation between decreased peptidyltransferase activity and increased -1 PRF in mutants of RPD3/MOF6 further supports this theory (Meskauskas et al. 2003), as does an independent study in E. coli demonstrating that changes in 


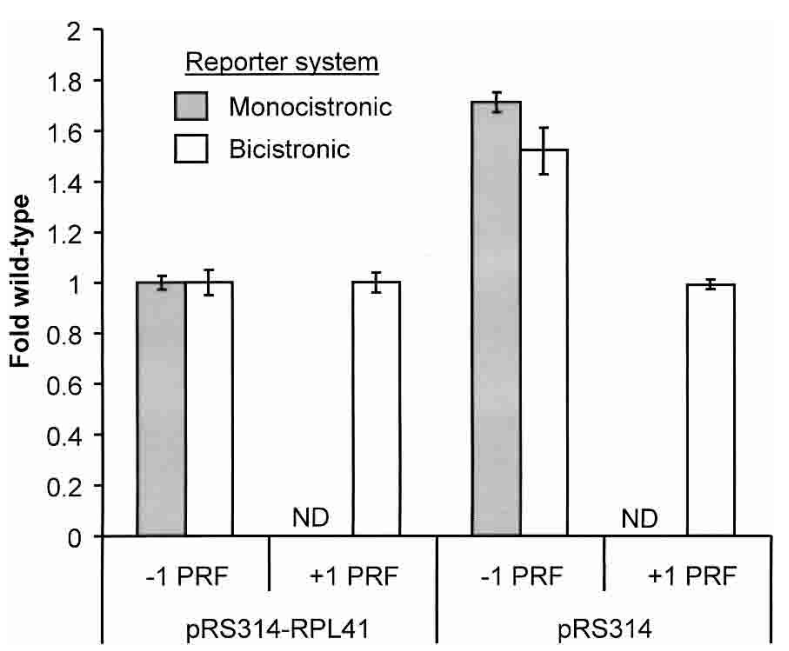

FIGURE 4. Programmed -1 ribosomal frameshifting is specifically stimulated in L41-deficient yeast cells. Isogenic XY5a strains (MATa ade2-1 trp1-1 his3-11,15 can1-100 ura3-1 leu2-3,112 rpl41a:: HIS3 $r p l 41 b::$ URA3) harboring pRS314-RPL41A or pRS314 were cotransformed with either monocistronic or bicistronic $\mathrm{p} 0, \mathrm{p}-1$ or $\mathrm{p}+1$ LEU2-CEN6-based reporter vectors. Changes in frameshift efficiencies are depicted in terms of fold wild-type (see Table 1). Programmed ribosomal frameshifting efficiencies using the monocistronic reporters were determined as described (Dinman et al. 1991; Peltz et al. 1999). ND: Not determined. In the assays using the bicistronic reporter system, Renilla and firefly luciferase activities of clarified cell lysates were determined using Dual-Luciferase Assay Reagents (Promega) and quantitiated using a TD20/20 lumineter (Turner designs). Frameshifting efficiencies were calculated by dividing the firefly/Renilla luminescence ratios from the -1 and +1 programmed frameshift test reporters by the 0 -frame control reporter. Each dataset represents the averages of three individual experiments repeated in triplicate. Error bars denote standard deviations from the means.

ribosomal pause times correlated with changes in programmed -1 ribosomal frameshifting (Masucci et al. 2002).

Protein synthesis is the primary function of the ribosome and peptidyltransfer is the most central molecular reaction. Thus, one question posed by this and another recent study (Dresios et al. 2002) is why significant growth phenotypes are not associated with cells harboring peptidyltransferasedefective ribosomes. An examination of the kinetics of each of the steps of translation elongation suggests the answer. In vitro measurements using E. coli derived ribosomes and cofactors reveal that, whereas the rates of peptidyltransfer $\left(20 \mathrm{~s}^{-1}\right)$ (Southworth et al. 2002) and EF-G catalyzed translocation $\left(18 \mathrm{~s}^{-1}\right)$ (Semenkov et al. 2000) are similar, the rate-limiting steps in elongation are aa-tRNA accommodation $\left(8 \mathrm{~s}^{-1}\right)$ and dissociation of EF-Tu.GDP from the ribosome $\left(4 \mathrm{~s}^{-1}\right)$ (Pape et al. 1998). Thus, even though these mutant ribosomes exhibit significant peptidyltransferase defects, rates of elongation are likely not significantly affected. However, it is possible that peptidyltransferase function was sufficiently decreased to render this step rate limiting in at least some of the $10 \%$ of rpl3 alleles that were found to be lethal in this study.

Comparison of ribosomes from all three superkingdoms reveals that there has been strong selection for conservation of the fine structure of this complex biomachine (Ban et al. 2000; Mueller et al. 2000; Morgan et al. 2000; Wimberly et al. 2000; Harms et al. 2001; Spahn et al. 2001; Yusupova et al. 2001). Comparison of the crystal structures of the $H$. marismortui 50S subunit at $2.4 \AA$ (Ban et al. 2000), the Thermus thermophilus $70 \mathrm{~S}$ ribosome at $5.5 \AA$ resolution (Yusupov et al. 2001), the Deinococcus radiodurans 50S subunit at $3.1 \AA$ (Harms et al. 2001), and the most recent cryo-EM analysis of the yeast $80 \mathrm{~S}$ ribosome (Spahn et al. 2001) reveals that the overall L3 structure and its placement in the ribosome is highly conserved between all of these organisms. Multiple sequence alignment of L3 protein sequences from six representative organisms (Homo sapiens, Drosophilia melanogaster, S. cerevisiae, H. Marismortui, E. coli, and T. thermophilus) reveals that the three residues genetically identified in this study are highly conserved (Fig. 5A). The proline (yeast P257) is universal. The tryptophan (yeast W255) is conserved in eukaryotes and archea. Notably, the corresponding glutamine in E. coli (Q298) is methylated, and lack of this modification results in a cold-sensitive phenotype (Lhoest and Colson 1981). We suggest that methylation of this glutamine in E. coli reduces its polarity, thus making the local environment more similar to that created by the tryptophan in the eukaryotic and archael systems. The isoleucine (yeast I282) is also conserved in eukaryotes with neutral changes to leucine in $H$. marismortui (L270), and valine in E. coli and T. thermophilus (V177 and V172, respectively).

Figure 5B depicts the H. marismortui $\mathrm{L} 3$ protein in relation to the rRNA environment surrounding the peptidyltransferase center. The tryptophan of L3 corresponding to yeast W255 is at the end of a "finger" that protrudes into the center of the large subunit. This marks the closest approach of any amino acid in the ribosome $(\sim 18 \AA)$ to the peptidyltransferase catalytic center (Yellow, E. coli A2451; H. marismortui 2486; yeast 2876). The observation that the double mutant (W255C + P257T) had no greater effect on either frameshifting or peptidyltransferase activity compared to $\mathrm{W} 255 \mathrm{C}$ alone suggests that this amino acid plays an important role in the formation and activity of the peptidyltransferase center. However, because mutation of the universally conserved proline (yeast P257) also resulted in strong peptidyltransferase inhibition and stimulation of -1 PRF, we suggest that its function may be to form an important bend in the finger so as to correctly position W255. The third residue (yeast I282) is in the hydrophobic core at the base of the finger: Although $\mathrm{I} \rightarrow \mathrm{T}$ is fairly conservative, we suspect that the addition of a polar hydroxyl side group is sufficient to alter the structure of the core, misaligning the finger. This would account for the observed effects of this mutant on both -1 PRF and peptidyltransferase activity.

L41 presents a particularly attractive target for potential antiviral therapeutics. One could envisage that small molecules able to interfere with or alter interactions between 

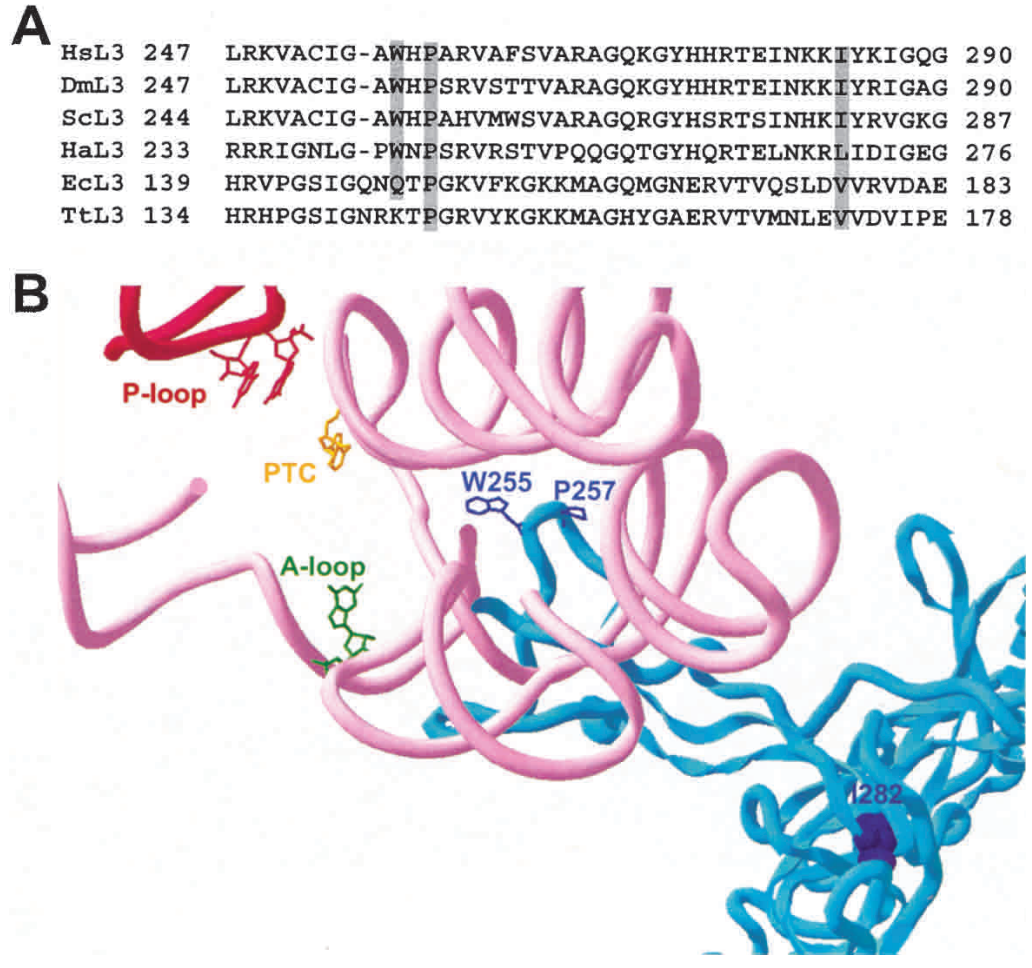

FIGURE 5. L3 and the peptidyltransferase center. (A) ClustalW alignment of selected regions of ribosomal protein L3. The rimary amino acid sequences from six representative species in the vicinity of the amino acids of L3 examined in this study were aligned. L3 sequences were from the following species: H. Sapiens (HsL3 from amino acids 247-290), D. melanogaster (DmL3, from amino acids 247-290), S. cerevisiae (ScL3 from residues 244-287), H. marismortui (HaL3 from residues 233-276), E. coli (EcL3 from residues 139-183), and T. thermophilus (TtL3 from amino acids 134-178). The three amino acids of interest to this study are highlighted. (B) Mapping of the L3 mutants within in the context of the H. marismortui 50 S crystal structure at $2.4 \AA$. L3 is colored blue. W255 and P257 are shown in stick outline, while I282 is shown in space filling mode. Helix 80 (P-loop) is indicated in red, and helices 89-93 are in pink. The peptidyltransferase center active site (PTC) is shown in yellow (H. marismortui 2486; E. coli A2451). The base of the 23S rRNA of the A-loop that interacts with the $3^{\prime}$ end of the aa-tRNA is shown in green ( $H$. marismoutui U2588; E. coli G2553), and those that interact with the $3^{\prime}$ end of the peptidyl-tRNA and P-site (H. marismortui G2284, G2285; E. coli G2252 and G2253) are in red.

L41 and the ribosome would result in ribosomes having decreased peptidyltransferase activities. This would promote increased -1 PRF efficiencies, which would, in turn, interfere with self assembly of -1 PRF-dependent viruses interfering with virus propagation. Thus, one would predict that such a class of small molecules would have antiviral properties. A number of specific properties of this protein make it a particularly attractive target. It is highly conserved from humans to yeast and its nonessential status in yeast suggests that inhibiting its function would not have a lethal impact on human cellular functions. Its extremely small size is also advantageous for both biophysical and economic reasons. At the physical level, the impact of synthetic small molecules would be expected to be greater on a protein of relatively similar size rather than a significantly larger one. Economically, chemical synthesis of 25 amino acid peptides is very inexpensive, enhancing the cost effectiveness of high throughput screens. The demonstrated reliance on -1 PRF of HIV-1 as well as the presumed reliance of the SARS-associated Coronavirus on this mechanism (Marra et al. 2003; Rota et al. 2003) suggests that the general findings presented here are of more than academic interest.

\section{MATERIALS AND METHODS}

\section{Strains, plasmids, genetic manipulation, and media}

E. coli $\mathrm{DH} 5 \alpha$ was used to amplify plasmid DNA. Transformation of yeast and E. coli were performed as described previously (Cui et al. 1995). YPAD, YPG, SD, synthetic complete medium $(\mathrm{H}-)$, and $4.7 \mathrm{MB}$ plates for testing the killer phenotype were as previously reported (Dinman and Wickner 1994). Restriction enzymes were obtained from Promega, MBI Fermentas, BRL, and Boehringer Mannheim. T4 DNA ligase and T4 DNA polymerase were obtained from Boehringer Mannheim and BioRAD, and precision Taq polymerase was obtained from Stratagene. Radioactive nucleotides were obtained from NEN. T7 Sequenase was obtained from USB and Sequagel-6 was obtained from National Diagnostics. DNA sequence analysis was performed by the UMDNJ-RWJMS DNA core facility. Oligonucleotide primers were purchased from IDT.

RW1906 (MATa leu2 mak8-1 $\mathrm{K}^{-}$) was a generous gift from Dr. Reed Wickner. PLY36

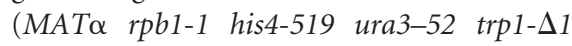
upf $1 \Delta::$ hisG) was a generous gift from Dr. Stuart Peltz. Strain XY5a (MATa ade2-1 trp1-1 his3-11,15 can1-100 ura3-1 leu2-3,112 rpl41a::HIS3 rpl41b::URA3) and pRS314-RPL41A were generous gifts from Dr. Jonathan Warner. The rpl3-knockout ( $r p l 3 \Delta)$ strain JD1090 (MATa ura3-52 lys2-801 trp18 leu $2^{=}$his $3=$ RPL3::HIS3 [L-AHNB $\mathrm{M}_{1}$ ]) was constructed as follows. The HIS3 gene was first prepared by amplifying it from pRS313 (Sikorski and Hieter 1989) with primers $5^{\prime}$ HISRPL3 and 3 ' HISRPL3 (Table 2). The resulting PCR fragment harboring ends homologous to sequences flanking the RPL3 gene was integrated into the RPL3 locus in the

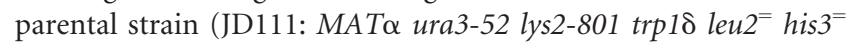
[L-AHNB $\mathrm{M}_{1}$ ]), harboring pRPL3-URA3. Disruption of the RPL3 locus on the chromosome in $\mathrm{His}^{+}$prototrophs was confirmed by (1) the inability of cells to grow in the presence of 5-FOA, (2) polymerase chain reaction using primers RPL3FOR and RPL3REV, and (3) Southern blot analysis. Oligonucleotide site directed mutagenesis (Kunkel 1985) was used to create pRPL3TRP1 based plasmids harboring the W255C and P257T alleles using the synthetic DNA oligonucleotides W255C and P257T (Table 2). Plasmids for expression of dual luciferase frameshift reporters were constructed by amplification of the coding region 
TABLE 1. Comparison of programmed ribosomal frameshifting efficiencies obtained from monocistronic versus bicistronic frameshift reporter plasmid systems

\begin{tabular}{|c|c|c|c|c|c|c|c|c|}
\hline \multicolumn{2}{|c|}{ Genetic background: } & \multicolumn{5}{|c|}{ JD1090 (rp/3s) } & \multicolumn{2}{|c|}{ XY5a $(r p / 41 A \Delta r p / 41 B \Delta)$} \\
\hline & Reporter & pRPL3 & pmak8 & pW255C & p257S & $\mathrm{pl} 282 \mathrm{~T}$ & pRS314-RPL41A & pRS314 \\
\hline \multirow[t]{2}{*}{$\%-1 \mathrm{PRF}$} & Monocistronic & $1.90 \pm 0.09$ & $4.76 \pm 0.14$ & $4.54 \pm 0.10$ & $4.50 \pm 0.05$ & $3.82 \pm 0.12$ & $1.7 \% \pm 0.05$ & $2.9 \pm 0.11$ \\
\hline & Bicistronic & $9.0 \pm 0.4$ & $14.5 \pm 0.2$ & $14.2 \pm 1.2$ & $13.9 \pm 1.3$ & $13.7 \pm 0.6$ & $13.1 \pm 0.6$ & $20.0 \pm 1.9$ \\
\hline \multirow[t]{2}{*}{$\%+1 \mathrm{PRF}$} & Monocistronic & $12.6 \pm 0.2$ & $13.8 \pm 0.6$ & $12.3 \pm 0.7$ & $11.3 \pm 1.0$ & $11.7 \pm 1.0$ & N.D. & N.D. \\
\hline & Bicistronic & $8.5 \pm 0.4$ & $7.7 \pm 0.4$ & $7.8 \pm 0.8$ & $8.8 \pm 0.6$ & $9.1 \pm 1.1$ & $20.0 \pm 0.8$ & $19.9 \pm 0.4$ \\
\hline
\end{tabular}

L-A directed programmed -1 and Ty/ directed programmed +1 frameshifting were determined in isogenic $r p / 3 \Delta$ or $r p / 41 A \Delta r p / 41 B \Delta$ strains harboring the indicated plasmid encoded alleles of $r p / 3$ or RPL41A using either lacZ-based monocistronic or dual-luciferase-based bicistronic reporter plasmid systems.

N.D.: Not determined. Values for percent programmed ribosomal frameshifting (PRF) and standard deviations are shown. All experiments were performed three times in triplicate.

of the dual luciferase reporter cassette with the intact polylinker from p2Luci (Grentzmann et al. 1998) by high-fidelity PCR and ligation of the product into p416 ADH (Mumberg et al. 1995). In this URA3 CEN6/ARSH4 plasmid, transcription of the dual-luciferase gene is driven by the $A D H 1$ promoter and proper $3^{\prime}$ end formation and polyadenylation is facilitated by the CYC1 terminator. Construction of the L-A -1 and and Ty1 +1 containing programmed frameshift dual-luciferase reporter plasmids were effected in a similar manner except that the frameshift signals from L-A and Ty1 were first amplified by PCR and subcloned into p2Luci before subsequent amplification and subcloning into p416 $\mathrm{ADH}$. The full details of the construction of these plasmids are described in an accompanying manuscript (Harger and Dinman 2003).

\section{Preparation and screening of a library of $r p / 3$ mutants}

To create a library of plasmid-borne rpl3 mutants, a strategy was devised so that DNA fragments harboring the coding region of RPL3 amplified by standard error-prone PCR mutagenesis methods (Costa and Weiner 1995) could be ligated into a pRS314 (TRP1)-based plasmid $3^{\prime}$ of the native RPL3 promoter, and $5^{\prime}$ of the RPL3 $3^{\prime}$ UTR. To make the parental plasmid construct, the RPL3 5' UTR was amplified from genomic DNA using the 5'
UASRPL3 and 3' UASRPL3 primers (Table 2). This was then cloned into pRS314 digested with Kpn I and Hind III. Subsequently, the RPL3 open reading frame was amplified from genomic DNA using the 5' RPL3ORF and 3' RPL3ORF primers (Table 2) and cloned into the Eco RI and Bam HI sites downstream of the 5' UTR. In the 3' UTR, the RPL3 gene was then amplified using the $5^{\prime}$ RPL3UTR and 3' RPL3UTR primers (Table 2), and the PCR product was cloned into the Not I and Sac I sites downstream of the RPL3 ORF. Digestion of the resulting plasmid (pRPL3-TRP1) with Eco RI and Bam HI was used to liberate it from the native RPL3 coding region, into which a library of PCR fragments were ligated. Due to the relatively large size of the RPL3 coding sequence, standard Taq polymerase was used to generate the PCR fragments. DNA sequence analysis confirmed that 19 of 20 randomly selected plasmids each contained 1 unique mutation per RPL3 coding region. The library was amplified in E. coli, introduced into JD1090 yeast cells by transformation, and after 3 days growth on selective medium (-trp) cells that had lost the wild-type RPL3 containing plasmids were identified by replica plating on 5-FOA (Rose et al. 1990). Colonies were replica plated onto killer indicator plates to identify those that had lost the killer virus phenotype. Plasmids were rescued from Killer ${ }^{-}$cells into $E$. coli, and reintroduced into JD1090 cells. Only those that were able to completely cure the cells of the killer phenotype were selected as new mak 8 alleles. Approximately $3 \times 0^{4}$ colonies were screened.

TABLE 2. Oligonucleotides used in this study

\begin{tabular}{ll}
\hline Primer name & \multicolumn{1}{c}{ Sequence } \\
\hline 5'HISRPL3 & 5'-GTTCAAGAATTGCTCGATAATTGCGAACAAACCATCTGCTAAGCCGGAAGTCATAACACAGTCC-3' \\
3'HISRPL3 & 5'-GGACGGGTTTACATGTTTAAATATATGTACATGTATGTAGTCTTATACCGTATAGAATGATACATTACC-3' \\
RPL3FOR & 5'-GAAATGTGCAAACCTTAG-3' \\
RPL3REV & 5'-GGAAATAGCAAACCAGAG-3' \\
5'UASRPL3 & 5'-CCCCGGTACCTCATGTACACTGGAATGAAT-3' \\
3'UASRPL3 & 5'-CCCCAAGCTTTGTAGTAACTGTGTTGTTC-3' \\
5'RPL3ORF & 5'-CCCCGAATTCAATCATGTCTCACAGAAAG-3' \\
3'RPL3ORF & 5'-CCCCGGATCCCCTTACAAGTCCTTCTTCAAAG-3' \\
5'RPL3UTR & 5'-CCCCGCGGCCGCGAAGTTTTGTTAGAAAATAAATC-3' \\
3'RPL3UTR & 5'-CCCCGAGCTCGGACGGGTTTACATGTTTAA-3' \\
W255C & 5'-GCTTGTATTGGTGCTTGCCATCCAGCCCACGTTG-3' \\
P257T & 5'-GTATTGGTGCTTGGCATTCAGCCCACGTTGCTTG-3' \\
\hline
\end{tabular}




\section{Assays for the killer phenotypes, measurement of frameshifting, and mRNA analyses}

The killer virus assay was carried out as previously described (Dinman and Wickner 1992). Briefly, yeast colonies were replica plated to $4.7 \mathrm{MB}$ plates newly seeded with 0.5 O.D. ${ }_{595}$ of the killer indicator strain $5 \times 47\left(M A T a / M A T \alpha\right.$ his $1 /+\operatorname{trp} 1 /+$ ura3 $\left./+\mathrm{K}^{-}\right)$per plate. After $2-3$ days at $20^{\circ} \mathrm{C}$, killer activity was observed as a zone of growth inhibition around the killer colonies. Killer virus assays were performed in multiple wild-type and mutant strains. Assays of programmed ribosomal frameshifting using monocistronic lac $Z$ reporter constructs were performed as previously described (Dinman et al. 1991; Peltz et al. 1999) using LEU2-CEN6 based series of 0 -frame control ( $\mathrm{p} 0)$, and -1 PRF $(\mathrm{p}-1)$ frameshift indicator vectors, or URA3-CEN6 based series of 0 -frame control ( $\mathrm{p} 0$ ) and Tyl-derived +1 PRF $(\mathrm{p}+1)$ frameshift indicator vectors. All assays were performed three times in triplicate to determine mean and standard deviations of frameshifting efficiencies. To monitor programmed -1 and +1 frameshifting using the dual luciferase reporter plasmids, glass beads were used to prepare lysates from cells expressing the 0 -frame, -1 ( $\mathrm{L}-\mathrm{A}$ derived), or +1 (Ty1 derived) dual-luciferase plasmids. After clarification of the lysates by centrifugation, typically $5 \mu \mathrm{L}$ were used in a total volume of $100 \mu \mathrm{L}$ of Dual-Luciferase Assay Reagents (Promega), and the Renilla and firefly luciferase activities were quantitiated using a TD20/20 luminometer (Turner designs). Frameshifting efficiencies were calculated by dividing the firefly/Renilla luminescence ratios from lysates of cells expressing the -1 or +1 programmed frameshift test reporters by the same ratio obtained from lysates of cells expressing the 0 -frame control reporter. All assays were performed three separate times each in triplicate. Extraction of total nucleic acids and RNA-RNA hybridizations to detect the presence of L-A and $M_{1}$ (-) strand RNAs were performed as previously described (Dinman and Wickner 1994). Nuclease protection assays were performed to monitor reporter mRNA abundances as previously described probing for the LacZ mRNAs generated from the $\mathrm{p} 0$ and p-1 plasmids (Harger et al. 2001). The abundance of mature $\mathrm{CYH} 2$ and CYH2-precursor mRNAs were determined by Northern blot analysis as previously described (Cui et al. 1996).

\section{Preparation of donor and acceptor tRNA fragments, ribosome purification, and puromycin reaction with purified fragments}

Yeast tRNAs were charged with $\left[{ }^{14} \mathrm{C}\right]$ Phenylalanine using a preparation of yeast tRNA synthetases purified by DEAE-cellulose treatment of yeast lysates as previously described (Wurmbach and Nierhaus 1979). Charged tRNAs were acetylated essentially as previously described (Haenni and Chapeville 1966) by resuspending $\left[{ }^{14} \mathrm{C}\right]$ Phe-tRNA ${ }^{\text {Phe }}$ in $280 \mu \mathrm{L}$ of $1.0 \mathrm{M}$ sodium acetate $(\mathrm{pH} 5.5)$ followed by addition of $28 \mu \mathrm{L}$ aliquots of acetic anhydride every 15 min for a total of $1 \mathrm{~h}$ at $0^{\circ} \mathrm{C}$. These reaction products were precipitated and washed with ethanol, resuspended in water, and $100 \%$ of the $\left[{ }^{14} \mathrm{C}\right]$ Phe-tRNA ${ }^{\text {Phe }}$ was determined to acetylated as judged by TLC chromatography. The acetyl- $\left[{ }^{14} \mathrm{C}\right] \mathrm{Phe}^{-} \mathrm{tRNA}{ }^{\text {Phe }}$ was subsequently digested with $500 \mathrm{U}$ of RNase T1 in $200 \mu \mathrm{L}$ of 0.3 $\mathrm{M}$ sodium acetate $\left(\mathrm{pH}\right.$ 5.0) for $1 \mathrm{~h}$ at $37^{\circ} \mathrm{C}$, and the reaction mixtures were purified using DEAE Sephadex as previously described (Pestka et al. 1970). The resulting acetyl- $\left[{ }^{14} \mathrm{C}\right]$ Phe-CACCA was used as the "donor" fragment in the puromycin assay. $80 \mathrm{~S}$ ribosomes were prepared from wild-type and mutant strains as described (Triana et al. 1994) with minor modifications. Briefly, cells were grown to early mid-log phase, spun down, and washed with Buffer A (5 mM Mg[ $\left.\mathrm{CH}_{3} \mathrm{COO}\right]_{2}, 20 \mathrm{mM}$ Tris- $\mathrm{HCl} \mathrm{pH} 7.5$ at $+4^{\circ} \mathrm{C}, 50 \mathrm{mM} \mathrm{KCl}, 10 \%$ Glycerol). Cells (6-20 g) were suspended in $25 \mathrm{~mL}$ of Buffer A and PMSF and DTE were added to final concentrations of $1 \mathrm{mM}$ each. Cells were disrupted with BeadBeater (Biospec Inc.) at $4^{\circ} \mathrm{C}$. Cell lysates were transferred to centrifuge tubes and spun $10 \mathrm{~min}$ at $4000 \mathrm{rpm}$ in a Sorvall SS34 rotor. A $4 \mathrm{M}$ stock solution of $\mathrm{KCl}$ was added to the supernatants to a final concentration of $0.5 \mathrm{M}$, and then centrifuged in an SS34 rotor for $45 \mathrm{~min}$ at $15,000 \mathrm{rpm}$. Supernatants were transferred to Beckman $14 \times 89 \mathrm{~mm}(13 \mathrm{~mL})$ tubes containing $3 \mathrm{~mL}$ of Buffer B (5 $\mathrm{mM} \mathrm{Mg}\left[\mathrm{CH}_{3} \mathrm{COO}\right]_{2}, 20 \mathrm{mM}$ Tris- $\mathrm{HCl} \mathrm{pH} 7.5$ at $30^{\circ} \mathrm{C}, 0.5 \mathrm{M} \mathrm{KCl}$, $10 \%$ Glycerol) and ribosomes were pelleted at $24,000 \mathrm{rpm}$ for 18-24 h. Ribosomes were treated with puromycin to strip endogenous peptidyl-tRNA, mRNA, and soluble factors from ribosomes. Pellets were washed to remove the fines by gentle mixing with Buffer B and ribosomes were resuspended in $1 \mathrm{~mL}$ of Buffer B containing $1 \mathrm{mM}$ PMSF and DTE. Puromycin and GTP, both at 1 $\mathrm{mM}$ final concentrations, were added and the mix was incubated for $30 \mathrm{~min}$ at $30^{\circ} \mathrm{C}$. Ribosomes were washed by pelleting twice through a $25 \%$ Glycerol cushion in the same buffer. The washed ribosomes were resuspended in Buffer C (50 mM Tris- $\mathrm{HCl} \mathrm{pH}$ 7.5, $5 \mathrm{mM} \mathrm{Mg}\left[\mathrm{CH}_{3} \mathrm{COO}\right]_{2}, 50 \mathrm{mM} \mathrm{NH}_{4} \mathrm{Cl}, 0.1 \mathrm{mM}$ PMSF, $0.1 \mathrm{mM}$ DTE, 25\% Glycerol), clarified by centrifugation for $5 \mathrm{~min}$ at 4000 $\mathrm{rpm}$, and ribosome concentrations were adjusted to 5-10 pmole/ $\mu \mathrm{L}\left(1 \mathrm{~A}_{260}\right.$ unit $=20$ pmole of $80 \mathrm{~S}$ subunits). Ribosomes were either immediately used or aliquotted and stored at $-80^{\circ} \mathrm{C}$. Puromycin reactions were performed as previously described (Diedrich et al. 2000) with slight modifications. Ribosomes ( 20 pmole) were incubated with 5 pmole of acetyl-CACCA $\left[{ }^{14} \mathrm{C}\right] \mathrm{Phe}(682$ d.p.m./ pmole) in $300 \mu \mathrm{L}$ of PR Buffer [25 mM HEPES-KOH pH 7.4, 135 $\left.\mathrm{mM} \mathrm{NH}_{4} \mathrm{Cl}, 250 \mathrm{mM} \mathrm{KCl}, 20 \mathrm{mM} \mathrm{MgCl}_{2}, 33 \% \mathrm{EtOH}\right]$ at $0^{\circ} \mathrm{C}$ for $10 \mathrm{~min}$. Puromycin was added to final concentrations of $1 \mathrm{mM}$, and reaction mixes were incubated on ice. At indicated time points $50-\mu \mathrm{L}$ aliquots were taken and reactions stopped by the addition of equal volumes of a $0.3 \mathrm{M} \mathrm{NaOAc}$ solution saturated with $\mathrm{MgSO}_{4}$. Peptidyl-puromycin was extracted with $1 \mathrm{~mL}$ of EtOAc, and the radioactivity was determined by liquid scintillation counting. In all the studies controls were performed in the absence of puromycin to determine the nonspecific extraction of CACCA $\left[{ }^{14} \mathrm{C}\right] \mathrm{AcPhe}$. Control values (generally less than $2 \%$ ) were subtracted from the values obtained in the presence of puromycin. All assays were performed in triplicate.

\section{Computational analysis of ribosome structure}

The crystal structure of the $H$. marismortui ribosome (Ban et al. 2000) was visualized using the Swiss PDB viewer.

\section{ACKNOWLEDGMENTS}

We would like to thank Reed Wickner for the gift of the original mak8-1 strain, Ewan Plant, Alexey Petrov, and Jennifer Baxter for both technical and editorial assistance, and Petr V. Sergiev, M.J. Fournier, Phil Farabaugh, Jonathan Jacobs, and Rachel Green for insightful discussions regarding ribosome structure and function. We also extend our sincere appreciation to Drs. Dennis Syntenos 
and Jonathan Warner for strains, plasmids, advice, and encouragement. This work was supported by grants to J.D.D. from the NIH (R01 GM58859), and the NSF (MCB-9807890).

The publication costs of this article were defrayed in part by payment of page charges. This article must therefore be hereby marked "advertisement" in accordance with 18 USC section 1734 solely to indicate this fact.

Received October 23, 2002; accepted May 22, 2003.

\section{REFERENCES}

Auron, P.E. and Fahnestock, S.R. 1981. Functional organization of the large ribosomal subunit of Bacillus stearothermophilus. J. Biol. Chem. 256: 10105-10110.

Balasundaram, D., Dinman, J.D., Wickner, R.B., Tabor, C.W., and Tabor, H. 1994. Spermidine deficiency increases +1 ribosomal frameshifting efficiency and inhibits Tyl retrotransposition in Saccharomyces cerevisiae. Proc. Natl. Acad. Sci. 91: 172-176.

Ban, N., Nissen, P., Hansen, J., Moore, P.B., and Steitz, T.A. 2000. The complete atomic structure of the large ribosomal subunit at $2.4 \AA$ resolution. Science 289: 905-920.

Belcourt, M.F. and Farabaugh, P.J. 1990. Ribosomal frameshifting in the yeast retrotransposon Ty: tRNAs induce slippage on a 7 nucleotide minimal site. Cell 62: 339-352.

Bernabeu, C., Conde, P., Vazquez, D., and Ballesta, J.P. 1979. Peptidyl transferase of bacterial ribosome: Resistance to proteinase K. Eur. J. Biochem. 93: 527-533.

Bidou, L., Stahl, G., Hatin, I., Namy, O., Rousset, J.-P., and Farabaugh, P.J. 2000. Nonsense-mediated decay mutants do not affect programmed -1 frameshifting. RNA 6: 952-961.

Clare, J.J., Belcourt, M., and Farabaugh, P.J. 1988. Efficient translational frameshifting occurs within a conserved sequence of the overlap between the two genes of a yeast Ty1 transposon. Proc. Natl. Acad. Sci. 85: 6816-6820.

Costa, G.L. and Weiner, M.P. 1995. Cloning and analysis of PCRgenerated DNA fragments. In PCR primer: A laboratory manual (eds. C.W. Dieffenbach and G.S. Dveksler), pp. 555-580. Cold Spring Harbor Laboratory Press, Cold Spring Harbor, NY.

Cui, Y., Hagan, K.W., Zhang, S., and Peltz, S.W. 1995. Identification and characterization of genes that are required for the accelerated degradation of mRNAs containing a premature translational termination codon. Genes \& Dev. 9: 423-436.

Cui, Y., Dinman, J.D., and Peltz, S.W. 1996. mof4-1 is an allele of the UPF1/IFS2 gene which affects both mRNA turnover and -1 ribosomal frameshifting efficiency. EMBO J. 15: 5726-5736.

Diedrich, G., Spahn, C.M., Stelzl, U., Schafer, M.A., Wooten, T., Bochkariov, D.E., Cooperman, B.S., Traut, R.R., and Nierhaus, K.H. 2000. Ribosomal protein L2 is involved in the association of the ribosomal subunits, tRNA binding to $\mathrm{A}$ and $\mathrm{P}$ sites and peptidyl transfer. EMBO J. 19: 5241-5250.

Dinman, J.D. and Wickner, R.B. 1992. Ribosomal frameshifting efficiency and Gag/Gag-pol ratio are critical for yeast $M_{1}$ doublestranded RNA virus propagation. J. Virol. 66: 3669-3676.

- 1994. Translational maintenance of frame: Mutants of Saccharomyces cerevisiae with altered -1 ribosomal frameshifting efficiencies. Genetics 136: 75-86.

Dinman, J.D., Icho, T., and Wickner, R.B. 1991. A -1 ribosomal frameshift in a double-stranded RNA virus forms a Gag-pol fusion protein. Proc. Natl. Acad. Sci. 88: 174-178.

Dinman, J.D., Ruiz-Echevarria, M.J, Czaplinski, K., and Peltz, S.W. 1997. Peptidyl transferase inhibitors have antiviral properties by altering programmed -1 ribosomal frameshifting efficiencies: Development of model systems. Proc. Natl. Acad. Sci. 94: 6606-6611.

Dinman, J.D., Ruiz-Echevarria, M.J., and Peltz, S.W. 1998. Translating old drugs into new treatments: Identifying compounds that modu- late programmed -1 ribosomal frameshifting and function as potential antiviral agents. Trends Biotechnol. 16: 190-196.

Dresios, J., Panopoulos, P., Suzuki, K., and Syntenos, D. 2003. A dispensable yeast ribosomal protein optimizes peptidyltransferase activity and affects translocation. J. Biol. Chem. 278: 3314-3322

Fabijanski, S. and Pellegrini, M. 1981. Identification of proteins at the peptidyl-tRNA binding site of rat liver ribosomes. Mol. Gen. Genet. 184: 551-556.

Fahnestock, S.R. 1975. Evidence of the involvement of a 50S ribosomal protein in several active sites. Biochemistry 14: 5321-5327.

Farabaugh, P.J. 1996. Programmed translational frameshifting. Microbiol. Rev. 60: 103-134.

Fried, H.M. and Warner, J.R. 1981. Cloning of yeast gene for trichodermin resistance and ribosomal protein L3. Proc. Natl. Acad. Sci. 78: $238-242$.

Gesteland, R.F. and Atkins, J.F. 1996. Recoding: Dynamic reprogramming of translation. Annu. Rev. Biochem. 65: 741-768.

Grentzmann, G., Ingram, J.A., Kelly, P.J., Gesteland, R.F., and Atkins, J.F. 1998. A dual-luciferase reporter system for studying recoding signals. RNA 4: 479-486.

Haenni, A.L. and Chapeville, F. 1966. The behavior of acetylphenylalanyl soluble ribonucleic acid in polyphenylalanine synthesis. Biochim. Biophys. Acta 114: 135-148.

Harger, J.W. and Dinman, J.D. 2003. An in vivo dual-luciferase assay system for studying translational recoding in the yeast Saccharomyces cerevisae. RNA (this issue).

Harger, J.W., Meskauskas, A., Nielsen, N., Justice, M.C., and Dinman, J.D. 2001. Tyl retrotransposition and programmed +1 ribosomal frameshifting require the integrity of the protein synthetic translocation step. Virology 286: 216-224.

Harger, J.W., Meskauskas, A., and Dinman, J.D. 2002. An "integrated model" of programmed ribosomal frameshifting and post-transcriptional surveillance. Trends Biosci. 27: 448-454.

Harms, J., Schluenzen, F., Zarivach, R., Bashan, A., Gat, S., Agmon, I., Bartels, H., Franceschi, F., and Yonath, A. 2001. High resolution structure of the large ribosomal subunit from a mesophilic eubacterium. Cell 107: 679-688.

Hudak, K.A., Hammell, A.B., Yasenchak, J., Tumer, N.E., and Dinman, J.D. 2001. A C-terminal deletion mutant of pokeweed antiviral protein inhibits programmed +1 ribosomal frameshifting and ty1 retrotransposition without depurinating the sarcin/ricin loop of rRNA. Virology 279: 292-301.

Icho, T. and Wickner, R.B. 1989. The double-stranded RNA genome of yeast virus L-A encodes its own putative RNA polymerase by fusing two open reading frames. J. Biol. Chem. 264: 6716-6723.

Jacks, T. 1990. Translational suppression in gene expression in retroviruses and retrotransposons. Curr. Top. Microbiol. Immunol. 157: 93-124.

Kawakami, K., Paned, S., Faioa, B., Moore, D.P., Boeke, J.D., Farabaugh, P.J., Strathern, J.N., Nakamura, Y., and Garfinkel, D.J. 1993. A rare tRNA-Arg(CCU) that regulates Ty1 element ribosomal frameshifting is essential for Tyl retrotransposition in Saccharomyces cerevisiae. Genetics 135: 309-320.

Khaitovich, P., Mankin, A.S., Green, R., Lancaster, L., and Noller, H.F. 1999. Characterization of functionally active subribosomal particles from Thermus aquaticus. Proc. Natl. Acad. Sci. 96: 85-90.

Kontos, H., Napthine, S., and Brierley, I. 2001. Ribosomal pausing at a frameshifter RNA pseudoknot is sensitive to reading phase but shows little correlation with frameshift efficiency. Mol. Cell. Biol. 21: 8657-8670.

Kunkel, T. 1985. Rapid and efficient site-specific mutagenesis without phenotype selection. Proc. Natl. Acad. Sci. 82: 488-492.

Lhoest, J. and Colson, C. 1981. Cold-sensitive ribosome assembly in an Escherichia coli mutant lacking a single methyl group in ribosomal protein L3. Eur. J. Biochem. 121: 33-37.

Lopinski, J.D., Dinman, J.D., and Bruenn, J.A. 2000. Kinetics of ribosomal pausing during programmed -1 translational frameshifting. Mol. Cell. Biol. 20: 1095-1103.

Marra, M.A., Jones, S.J., Astell, C.R., Holt, R.A., Brooks-Wilson, A., 
Butterfield, Y.S., Khattra, J., Asano, J.K., Barber, S.A., Chan, S.Y., et al. 2003. The genome sequence of the SARS-associated coronavirus. Science 300: 1399-1404.

Masucci, J.P., Gallant, J., Lindsley, D., and Atkinson, J. 2002. Influence of the relA gene on ribosome frameshifting. Mol. Genet. Genomics 268: $81-86$.

Meskauskas, A., Baxter, J.L., Carr, E.A., Yasenchak, J., Gallagher, J.E.G., Baserga, S.J., and Dinman, J.D. 2003. Delayed rRNA processing results in significant ribosome biogenesis and functional defects. Mol. Cell. Biol. 23: 1602-1613.

Morgan, D.G., Menetret, J.F., Radermacher, M., Neuhof, A., Akey, I.V., Rapoport, T.A., Akey, C.W. 2000. A comparison of the yeast and rabbit $80 \mathrm{~S}$ ribosome reveals the topology of the nascent chain exit tunnel, inter-subunit bridges and mammalian rRNA expansion segments. J. Mol. Biol. 301: 301-321.

Mueller, F., Sommer, I., Baranov, P., Matadeen, R., Stoldt, M., Wohnert, J., Gorlach, M., van Heel, M., and Brimacombe, R. 2000. The $3 \mathrm{D}$ arrangement of the $23 \mathrm{~S}$ and $5 \mathrm{~S}$ rRNA in the Escherichia coli $50 \mathrm{~S}$ ribosomal subunit based on a cryo-electron microscopic reconstruction at $7.5 \AA$ resolution. J. Mol. Biol. 298: 35-59.

Muhlrad, D. and Parker, R. 1999. Recognition of yeast mRNAs as "nonsense containing" leads to both inhibition of mRNA translation and mRNA degradation: Implications for the control of mRNA decapping. Mol. Biol. Cell 11: 3971-3978.

Mumberg, D., Muller, R., and Funk, M. 1995. Yeast vectors for the controlled expression of heterologous proteins in different genetic backgrounds. Gene 156: 119-122.

Ohtake, Y. and Wickner, R.B. 1995. Yeast virus propagation depends critically on free $60 \mathrm{~S}$ ribosomal subunit concentration. Mol. Cell. Biol. 15: 2772-2781.

Pape, T., Wintermeyer, W., and Rodnina, M.V. 1998. Complete kinetic mechanism of elongation factor Tu-dependent binding of aminoacyl-tRNA to the A site of the E. coli ribosome. EMBO J. 17: 7490-7497.

Peltz, S.W., Hammell, A.B., Cui, Y., Yasenchak, J., Puljanowski, L., and Dinman, J.D. 1999. Ribosomal protein 13 mutants alter translational fidelity and promote rapid loss of the yeast killer virus. Mol. Cell. Biol. 19: 384-391.

Pestka, S., Hishizawa, T., and Lessard, J.L. 1970. Studies on the formation of transfer ribonucleic acid-ribosome complexes. 8. Aminoacyl oligonucleotide binding to ribosomes: characteristics and requirements. J. Biol. Chem. 245: 6208-6219.

Plant, E.P., Muldoon Jacobs, K.I., Harger, J.W., Meskauskas, A., Jacobs, J.L., Baxter, J.L., Petrov, A.N., and Dinman, J.D. 2003. The 9-Å solution: How mRNA pseudoknots promote efficient programmed -1 ribosomal frameshifting. RNA 9: 168-174.

Rose, M.D., Winston, F., and Hieter, P. 1990. Methods in yeast genetics. Cold Spring Harbor Laboratory Press, Cold Spring Harbor, NY.

Rota, P.A., Oberste, M.S., Monroe, S.S., Nix, W.A., Campagnoli, R., Icenogle, J.P., Penaranda, S., Bankamp, B., Maher, K., Chen, M.H., et al. 2003. Characterization of a novel coronavirus associated with severe acute respiratory syndrome. Science 300: 1394-1399.

Schulze, H. and Nierhaus, K.H. 1982. Minimal set of ribosomal components for reconstitution of the peptidyltransferase activity. EMBO J. 1: 609-613.
Semenkov, Y.P., Rodnina, M.V., and Wintermeyer, W. 2000. Energetic contribution of tRNA hybrid state formation to translocation catalysis of the ribosome. Nat. Struct. Biol. 7: 1027-1031.

Sikorski, R.S. and Hieter, P. 1989. A system of shuttle vectors and yeast host strains designed for efficient manipulation of DNA in Saccharomyces cerevisiae. Genetics 122: 19-27.

Southworth, D.R., Brunelle, J.L., and Green, R. 2002. EFG-independent translocation of the mRNA:tRNA complex is promoted by modification of the ribosome with thiol-specific reagents. J. Mol. Biol. 324: 611-623.

Spahn, C.M., Beckmann, R., Eswar, N., Penczek, P.A., Sali, A., Blobel, G., and Frank, J. 2001. Structure of the 80 S ribosome from Saccharomyces cerevisiae - tRNA- ribosome and subunit-subunit interactions. Cell 107: 373-386.

Suzuki, K., Hashimoto, T., and Otaka, E. 1990. Yeast ribosomal proteins: XI. Molecular analysis of two genes encoding YL41, an extremely small and basic ribosomal protein, from Saccharomyces cerevisiae. Curr. Genet. 17: 185-190.

Triana, F., Nierhaus, K.H., and Chakraburtty, K. 1994. Transfer RNA binding to $80 \mathrm{~S}$ ribosomes from yeast: Evidence for three sites. Biochem. Mol. Biol. Int. 33: 909-915.

Tumer, N.E., Parikh, B., Li, P., and Dinman, J.D. 1998. Pokeweed antiviral protein specifically inhibits Tyl directed +1 ribosomal frameshifting and Ty1 retrotransposition in Saccharomyces cerevisiae. J. Virol. 72: 1036-1042.

Tzeng, T.H., Tu, C.L., and Bruenn, J.A. 1992. Ribosomal frameshifting requires a pseudoknot in the Saccharomyces cerevisiae doublestranded RNA virus. J. Virol. 66: 999-1006.

Wickner, R.B. 1996. Double-stranded RNA viruses of Saccharomyces cerevisiae. Microbiol. Rev. 60: 250-265.

Wickner, R.B. and Leibowitz, M.J. 1974. Chromosomal and non-chromosomal mutations affecting the "killer character" of Saccharomyces cerevisiae. Genetics 76: 423-432.

Wickner, R.B., Porter-Ridley, S., Fried, H.M., and Ball, S.G. 1982. Ribosomal protein L3 is involved in replication or maintenance of the killer double-stranded RNA genome of Saccharomyces cerevisiae. Proc. Natl. Acad. Sci. 79: 4706-4708.

Wimberly, B.T., Brodersen, D.E., Clemons Jr., W.M., Morgan-Warren, R.J., Carter, A.P., Vonrhein, C., Hartsch, T., and Ramakrishnan, V. 2000. Structure of the $30 \mathrm{~S}$ ribosomal subunit. $\mathrm{Na}$ ture 407: 327-339.

Wurmbach, P. and Nierhaus, K.H. 1979. Isolation of the protein synthesis elongation factors EF-Tu, EF-Ts, and EF-G from Escherichia coli. Methods Enzymol. 60: 593-606.

Xu, J. and Boeke, J.D. 1990. Host genes that influence transposition in yeast: the abundance of a rare tRNA regulates Tyl transposition frequency. Proc. Natl. Acad. Sci. 87: 8360-8364.

$\mathrm{Yu}, \mathrm{X}$. and Warner, J.R. Expression of a micro-protein. 2001. J. Biol. Chem. 276: 33821-33825.

Yusupov, M.M., Yusupova, G.Z., Baucom, A., Lieberman, K., Earnest, T.N., Cate, J.H., and Noller, H.F. 2001. Crystal structure of the ribosome at $5.5 \AA$ resolution. Science 292: 883-896.

Yusupova, G.Z., Yusupov, M.M., Cate, J.H., and Noller, H.F. 2001. The path of messenger RNA through the ribosome. Cell 106: 233241. 

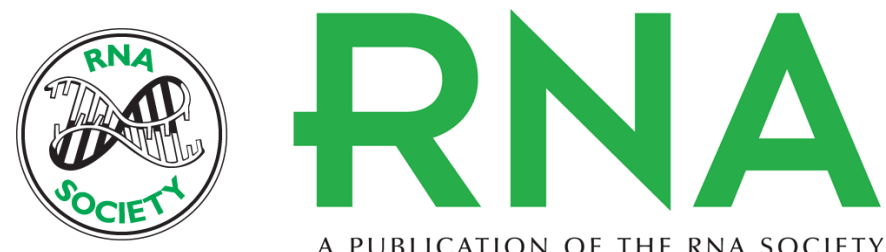

A PUBLICATION OF THE RNA SOCIETY

\section{Decreased peptidyltransferase activity correlates with increased programmed -1 ribosomal frameshifting and viral maintenance defects in the yeast Saccharomyces cerevisiae}

ARTURAS MESKAUSKAS, JASON W. HARGER, KRISTI L. MULDOON JACOBS, et al.

RNA 2003 9: 982-992

References This article cites 66 articles, 38 of which can be accessed free at:

http://rnajournal.cshlp.org/content/9/8/982.full.html\#ref-list-1

\section{License}

Email Alerting

Receive free email alerts when new articles cite this article - sign up in the box at the Service

top right corner of the article or click here.

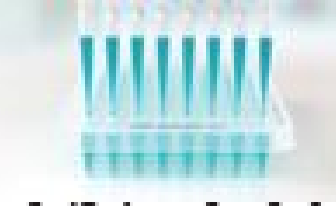

Providing Precise Solutions for your research.

To subscribe to RNA go to:

http://rnajournal.cshlp.org/subscriptions 